\title{
Intuitive physics and intuitive psychology ("theory of mind") in offspring of mothers with psychoses
}

Offspring of individuals with psychoses sometimes display an abnormal development of cognition, language, motor performance, social adaptation, and emotional functions. The aim of this study was to investigate the ability of children of mothers with schizophrenia $(n=28)$ and bipolar disorder $(n=23)$ to understand mental states of others using the Eyes Test (folk psychology or "theory of mind") and physical causal interactions of inanimate objects (folk physics). Compared with healthy controls $(n=29)$, the children of mothers with schizophrenia displayed significantly impaired performances on the Eyes Test but not on the folk physics test when corrected for IQ. The children of mothers with bipolar disorder did not differ from the controls. The folk physics test showed a significant covariance with IQ, whereas the Eyes Test did not exhibit such covariance. These results suggest that the attribution of mental states, but not the interpretation of causal interaction of objects, is impaired in offspring of individuals with schizophrenia, which may contribute to social dysfunctions. 
14 University of Szeged, Faculty of Medicine, Department of Physiology, Szeged, Hungary

15 Budapest University of Technology and Economics, Department of Cognitive Science, Budapest,

21 Correspondence: Szabolcs Kéri, University of Szeged, Department of Physiology, Dóm 22 sq. 10, H6720, Szeged, Hungary. E-mail: keri.szabolcs.gyula@med.u-szeged.hu; 23 szkeri2000@yahoo.com; Tel.: +36-20-448-3530, Fax: +36-62-545-842. 
INTRODUCTION

Several studies provided evidence that offspring of individuals with schizophrenia display an abnormal development of cognition, language, motor performance, social adaptation, and emotional functions (Niemi et al., 2003). Children who later develop bipolar disorder also show developmental and behavioral abnormalities, but these are less severe than that seen in children who later develop schizophrenia (Murray et al., 2004). In spite of extensive research in the field, the basic mechanisms of social and cognitive impairments in children of individuals with psychoses are poorly understood.

To elucidate this issue, we selected the evolutionary framework of folk psychology and folk physics, which is based on the classification of objects in our environment as agents and non-agents (Dennett, 1987; Sperber et al., 1995; Csibra et al., 1999; Baron-Cohen et al., 2001). and their movements are initiated by another object. From infancy, humans use folk or intuitive psychology to deduce the mental causes of agents ' actions and use folk or intuitive physics to deduce the physical causes of non-agents' movements. The term "theory of mind" is closely related to folk psychology and refers to the ability to infer one's own and other persons' mental states. Evidence suggests that "theory of mind" is impaired in patients with schizophrenia and may contribute to language and social dysfunctions (Frith, 2004; Brune, 2005). However, "theory of mind" is also impaired in patients with bipolar disorder (Kerr et al., 2003; Bora et al., 2005) and depression (Lee et al., 2005), which suggests that it is not specific to schizophrenia.

The aim of this study was to investigate folk psychology ("theory of mind") and folk physics in children of mothers with schizophrenia and psychotic bipolar disorder using the methods of Baron-Cohen et al. (2001). We addressed the following questions: (i) Are folk psychology and folk physics equally affected in the children of mothers with schizophrenia and bipolar disorder? (ii) Are the offspring of individuals with schizophrenia and bipolar disorder impaired relative to controls with negative family history for psychotic disorders? Our hypotheses was that children of mothers with schizophrenia would display a significant and generalized deficit in both folk psychology and folk physics tests, whereas the children of mothers with bipolar disorder would be much less severely affected (Murray et al., 2004). 
MATERIALS AND METHODS

\section{Participants}

Mothers with schizophrenia and with type I bipolar disorder with psychotic features were recruited at the National Psychiatric Center, Budapest, Hungary. Parents of control participants were university and hospital employees and their relatives or acquaintances. Diagnoses were based on the DSM-IV criteria (American Psychiatric Association, 2004). All mothers received the MINI International Neuropsychiatric Interview Plus (Sheehan et al., 1998) and their full medical records were available. Mothers with schizophrenia and type I bipolar disorder did not differ in illness duration (schizophrenia: 12.8 years, $\mathrm{SD}=5.6$; bipolar disorder: $14.2, \mathrm{SD}=8.2$ ) and in the number of acute hospitalizations (schizophrenia: 6.0, $\mathrm{SD}=4.1$; bipolar disorder: 5.3, $\mathrm{SD}=6.9$ ).

General intellectual functions were assessed with the Wechsler Intelligence Scale for Children - IV (WISC-IV) (Wechsler, 2003; Bass et al., 2008). Health cards of the children were obtained from their home districts and a detailed history was obtained from the families, including the non-affected parent. The following items were taken into consideration for the general description of the sample: obstetric complications, severe childhood illness, emotional symptoms, conduct problems, and academic impairment in the school (Table 1). After a complete description of the study, all parents (including the non-affected parents) gave their written informed consent. The study was approved by the institutional ethics board and was done in accordance with the Declaration of Helsinki.

\section{Folk Psychology}

The modified version of the Eyes Test was used (Baron-Cohen et al., 2001). The test consists of 28 photographs of the eye region of faces. The participant is asked to choose which of 4 words best describes what the person on the photograph is thinking and feeling. The eye regions reflect complex mental states and social emotions such as surprised, friendly, sure about something, worried or joking (Fig. 1A). As a control condition, participants were asked to judge the gender of the person using information from the eye region only.

\section{Folk Physics}

The folk physics test of Baron-Cohen et al. (2001) was used. The test consists of 20 items presented on separate cards. Items comprised physical problems based on the causal interactions of inanimate non-agents. Participants were asked to choose the right answer from 4 alternatives. Examples are shown in Fig. 1B. The problems presented by the folk physics test could be solved 
using common experiences of the physical world and were based on causal relationships. Similar to that reported by Baron-Cohen et al. (2001), our survey revealed that these problems are not included in standard school curriculum. Both folk psychology and folk physics tests have good psychometric properties.

\section{Data analysis}

The STATISTICA 6.0 (StatSoft, Inc., Tulsa) software was used for data analysis. The normality of data distribution was checked using Kolmogorov-Smirnov tests. The percentage of correct judgments in the folk psychology and folk physics tests was entered into an analysis of variance (ANOVA), followed by planned comparisons with $F$ tests. Analyses of covariance (ANCOVAs) were applied to control the effect of IQ in relation to folk psychology and folk physics performance. The level of significance was alpha $<.05$.

\section{RESULTS}

The demographic parameters of the participants are depicted in Table 1. In each group, children judged the gender of the actors and actresses in the Eyes Test with a high accuracy ( $>$ 90\%). A one-way ANOVA conducted on the IQ scores did not indicate a significant main effect of group $(p>.1)$.

The ANOVA conducted on the folk psychology and folk physics performances indicated significant main effects of group $(F(2,77)=9.8, p<.001)$ and task type $(F(1,77)=97.42, p<$. 001). The two-way interaction was not significant $(p=.6)$. Planned comparisons revealed that the children of mothers with schizophrenia performed worse on the Eyes Test relative to the control participants $(F(1,77)=10.32, p<.005)$. In the case of the folk physics test, the difference between the children of mothers with schizophrenia and the controls reached the level of statistical significance $(F(1,77)=3.84, p=0.05)$ (Fig. 2). When the children of mothers with bipolar disorder were compared with the controls, there were no significant between-group differences for either the Eyes Test or the folk physics test $(F<1, p>.3)$ (Fig. 2). There was no significant difference between boys and girls $(p>.1)$.

Next, we investigated the covariance between the folk psychology and folk physics tests and IQ. In the case of the Eyes Test, the main effect of group remained significant when IQ was included in the ANCOVA $(F(2,76)=6.36, p<.005)$, and the effect of IQ was not significant $(p$ $=.3$ ). However, in the case of the folk physics test, the main effect of the group was not 
118 significant $(p=0.1)$, but the effect of IQ exceeded the level of statistical significance $(\mathrm{F}(1,76)=$

$11910.46, p<.005)$.

\section{DISCUSSION}

121 We found that folk psychology ("theory of mind") was significantly impaired in children

122 of mothers with schizophrenia but not in children of mothers with bipolar disorder. This is

123 consistent with the view that schizophrenia vulnerability is associated with more severe early

124 impairments than vulnerability to bipolar disorder (Murray et al., 2004). Although the children of

125 mothers with schizophrenia also achieved lower scores on the folk physics test as compared with

126 the controls, this difference did not reach the level of statistical significance when it was

127 corrected for IQ. It is important to note that the folk physics test was more difficult than the folk

128 psychology test, which is consistent with the findings of Baron-Cohen et al. (2001). Moreover,

129 folk physics showed a significant covariance with IQ in contrast to folk psychology, which

130 suggests that the former one is more strongly influenced by general intellectual abilities and

131 logical reasoning. Differences among groups in folk physics therefore may be explained by

132 differences in IQ.

133 The fact that we found intact performances on the gender identification test is against a

134 generalized and profound deficit of facial processing, although the difficulty of this task was not

135 matched to that of the folk psychology procedure. Altogether, our results suggest that offspring of

136 individuals with schizophrenia show more pronounced impairments in the understanding of

137 mental states of agents than in the understanding of physical causality. This may contribute to

138 social dysfunctions (Fett et al., 2011).

139 Baron-Cohen et al. (2001) raised the possibility that folk psychology and folk physics are

140 potentially dissociable, which is consistent with the present results. Children with Asperger

141 syndrome displayed impaired performances on the Eyes Test, whereas they outperformed the

142 healthy control group on the folk physics test. This suggests an extreme "technical brain" and a

143 poorly functioning "social brain" in Asperger syndrome. The possible existence of extreme

144 "social brain" and "master mindreaders" has also been suggested (Dziobek et al., 2005). Indeed,

145 evidence from brain imaging and lesion studies indicates that several brain areas, including the

146 dorsomedial prefrontal cortex, superior temporal cortex, and amygdala specifically participate in

147 folk psychology and may be especially affected in psychiatric disorders such as autism-spectrum

148 disorders and schizophrenia (Adolphs, 2003; Lee et al., 2004). This neuronal system is

149 qualitatively different from that activated during logical reasoning (Goel \& Dolan, 2001). 
Fahim et al. (2004) found impaired activations of cortical areas related to emotional

151 memory in a discordant twin pair for schizophrenia. Brain structures associated with the

152 processing of facial information, such as the fusiform gyrus, may be especially vulnerable

153 (Onitsuka et al., 2003; Mancini-Marie et al., 2004). Platek et al. (2005) demonstrated a

154 relationship between abnormal medial prefrontal activation, schizotypal traits, and Eyes Test

155 performance, which raises the possibility that subclinical symptoms may be present in children at

156 risk of schizophrenia. Indeed, well-functioning adult relatives of schizophrenia patients without

157 schizotypal traits show normal performances on the Eyes Test (Kelemen et al., 2004). Others

158 found subtle deficits (Montag et al., 2012). The Eyes Test is not a simple emotion recognition

159 paradigm because the words include both affective and non-affective mental state terms and brain

160 areas specifically related to "theory of mind" are activated during the task (Calder et al., 2000).

161 The present study is not without limitations. First, the sample size was small, which

162 results in low statistical power. However, the participants comprised a unique population

163 (children of mothers with psychotic disorders), which limits the recruitment process. Second,

164 there was no comprehensive neuropsychological assessment and evaluation of subclinical

165 symptoms due to time limitations and the availability and willingness of the participants. We had

166 no information about the potential presence of endophenotypes in the control group.

167 In conclusion, the present findings may facilitate the delineation of cognitive foundations

168 of developmental abnormalities in children at potential risk of psychosis. One of the most

169 important aims of future research is to find endophenotypes that support the identification of

170 susceptibility and modifying genes and their interactions with environmental factors (Gottesman

171 \& Gould, 2003; Kéri \& Janka, 2004), and to establish clinically useful behavioral and neuronal

172 phenotypes that predict the development of different types of psychoses in high-risk individuals

173 (e.g., Dazzan et al., 2012). These neurobehavioral phenotypes should be complemented by

174 complex genetic-molecular-cellular biomarkers, taking into consideration the inherent ethical

175 aspects of such approaches. 


\section{ACKNOWLEDGEMENTS}

177 This study was supported by the National Brain Research Project.

178

179 


\section{REFERENCES}

181

182

183

184

185

186

187

188

189

190

191

192

193

194

195

196

197

198

199

200

201

202

203

204

205

206

207

208

209

210

211

212

213

Adolphs R. 2003. Cognitive neuroscience of human social behaviour. Nature Reviews

Neuroscience 4:165-178

American Psychiatric Association. 1994. DSM-IV: Diagnostic and Statistical Manual of Mental Disorders, $4^{\text {th }}$ ed. Washington, DC: American Psychiatric Press.

Baron-Cohen S, Wheelwright S, Spong A, Scahill V, Lawson J. 2001. Are intuitive physics and intuitive psychology independent? A test with children with Asperger Syndrome. Journal of Developmental and Learning Disorders 5:47-78

Bass L, Kő N, Kuncz E, Lányiné Engelmayer Á, Mészáros A, Mlinkó R, Nagyné Réz I, Rózsa S. 2008. Tapasztalatok a WISC-IV gyermek-intelligenciateszt magyarországi standardizálásáról. Budapest: Educatio.

Bora E, Vahip S, Gonul AS, Akdeniz F, Alkan M, Ogut M, Eryavuz A. 2005. Evidence for theory of mind deficits in euthymic patients with bipolar disorder. Acta Psychiatrica Scandinavica 112:110-116

Brune M. 2005. "Theory of mind" in schizophrenia: a review of the literature. Schizophrenia Bulletin 31:21-42

Calder AJ, Lawrence AD, Keane J, Scott SK, Owen AM, Christoffels I, Young AW. 2000.

Reading the mind from eye gaze. Neuropsychologia 40:1129-1138

Csibra G, Gergely Gy, Biró S, Koós O, Brockbank M. 1999. Goal attribution without agency cues: the perception of 'pure reason' in infancy. Cognition 72:237-267

Dazzan P, Soulsby B, Mechelli A, Wood SJ, Velakoulis D, Phillips LJ, Yung AR, Chitnis X, Lin A, Murray RM, McGorry PD, McGuire PK, Pantelis C. 2012. Volumetric abnormalities predating the onset of schizophrenia and affective psychoses: an MRI study in subjects at ultrahigh risk of psychosis. Schizophrenia Bulletin 38:1083-1091 
214 Dennett D. 1987. The Intentional Stance. Cambridge, Mass: MIT Press.

216 Dziobek I, Rogers K, Fleck S, Hassenstab J, Gold S, Wolf OT, Convit A. 2005. In search of

217 "master mindreaders": are psychics superior in reading the language of the eyes? Brain and

218 Cognition 58:240-244

219

220 Fahim C, Stip E, Mancini-Marie A, Beauregard M. 2004. Genes and memory: the neuroanatomical correlates of emotional memory in monozygotic twin discordant for 222 schizophrenia. Brain and Cognition 55:250-253

Fett AK, Viechtbauer W, Dominguez MD, Penn DL, van Os J, Krabbendam L. 2011. The relationship between neurocognition and social cognition with functional outcomes in schizophrenia: a meta-analysis. Neuroscience and Biobehavioral Reviews 35:573-588

Frith CD. 2004. Schizophrenia and theory of mind. Psychological Medicine 34:385-389

Goel V, Dolan RJ. 2001. Functional neuroanatomy of three-term relational reasoning.

231 Neuropsychologia 39:901-909

Gottesman I, Gould TD. 2003. The endophenotype concept in psychiatry: etymology and strategic intentions. American Journal of Psychiatry 160:636-645

235

Kelemen O, Kéri S, Must A, Benedek G, Janka Z. 2004. No evidence for impaired 'theory of mind' in unaffected first-degree relatives of schizophrenia patients. Acta Psychiatrica Scandinavica 110:146-149

Kéri S, Janka Z. 2004. Critical evaluation of cognitive dysfunctions as endophenotypes of schizophrenia. Acta Psychiatrica Scandinavica 110:83-91

Kerr N, Dunbar RI, Bentall RP. 2003. Theory of mind deficits in bipolar affective disorder.

244 Journal of Affective Disorders 73:253-259

246 Lee KH, Farrow TF, Spence SA, Woodruff PW. 2004. Social cognition, brain networks and 247 schizophrenia. Psychological Medicine 34:391-400 
248 Lee L, Harkness KL, Sabbagh MA, Jacobson JA. 2005. Mental state decoding abilities in clinical

249 depression. Journal of Affective Disorders 86:247-258

Mancini-Marie A, Stip E, Fahim C, Mensour B, Leroux JM, Beaudoin G, Bentaleb LA,

252 Bourgouin P, Beauregard M. 2004. Fusiform gyrus and possible impairment of the recognition of

253 emotional expression in schizophrenia subjects with blunted affect: a fMRI preliminary report.

254 Brain and Cognition 54:153-155

255

256

Montag C, Neuhaus K, Lehmann A, Krüger K, Dziobek I, Heekeren HR, Heinz A, Gallinat J.

2012. Subtle deficits of cognitive theory of mind in unaffected first-degree relatives of

schizophrenia patients. European Archives of Psychiatry and Clinical Neurosciences 262: 217-

259

226

Murray RM, Sham P, Van Os J, Zanelli J, Cannon M, McDonald C. 2004. A developmental model for similarities and dissimilarities between schizophrenia and bipolar disorder.

Schizophrenia Research 71:405-416

Niemi LT, Suvisaari JM, Tuulio-Henriksson A, Lonnqvist JK. 2003. Childhood developmental abnormalities in schizophrenia: evidence from high-risk studies. Schizophrenia Research 60:239258

Onitsuka T, Shenton ME, Kasai K, Nestor PG, Toner SK, Kikinis R, Jolesz FA, McCarley RW. of General Psychiatry 60:349-355

Platek SM, Fonteyn LC, Izzetoglu M, Myers TE, Ayaz H, Li C, Chance B. 2005. Functional near infrared spectroscopy reveals differences in self-other processing as a function of schizotypal personality traits. Schizophrenia Research 73:125-127 International Neuropsychiatric Interview (M.I.N.I.): the development and validation of a structured diagnostic psychiatric interview for DSM-IV and ICD-10. Journal of Clinical Psychiatry 59 (suppl. 20):22-33 
282 Sperber D, Premack D, Premack A. 1995. Causal Cognition: A Multidisciplinary Debate. Oxford:

283 Oxford University Press.

284

285 Wechsler D. 2003. The WISC-IV technical and interpretive manual. San Antonio, TX:

286 Psychological Corporation.

287

288

289

290

291

292

293

294 


\section{Table 1 (on next page)}

Demographic characteristics of the participants 


\begin{tabular}{|c|c|c|c|}
\hline & $\begin{array}{l}\text { Children of mothers } \\
\text { with schizophrenia } \\
(n=28)\end{array}$ & $\begin{array}{l}\text { Children of mothers } \\
\text { with bipolar disorder } \\
(n=23)\end{array}$ & $\begin{array}{l}\text { Control children } \\
(n=29)\end{array}$ \\
\hline Mean age (years) & $10.6(S D=0.8)$ & $10.8(S D=0.5)$ & $10.6(S D=0.9)$ \\
\hline Gender (boys/girls) & $20 / 8$ & $18 / 5$ & $16 / 3$ \\
\hline $\mathrm{IQ}$ & $96.6(S D=12.4)$ & $102.8(S D=11.3)$ & $101.9(S D=10.5)$ \\
\hline $\begin{array}{l}\text { Obstetric } \\
\text { complications }\end{array}$ & $1 / 28$ & $1 / 23$ & $1 / 29$ \\
\hline $\begin{array}{l}\text { Severe childhood } \\
\text { illness }\end{array}$ & $1 / 28$ & $1 / 23$ & $2 / 29$ \\
\hline Emotional symptoms & $6 / 28$ & $4 / 23$ & $0 / 29$ \\
\hline Conduct problems & $3 / 28$ & $4 / 23$ & $1 / 29$ \\
\hline $\begin{array}{l}\text { Academic } \\
\text { impairment }\end{array}$ & $5 / 28$ & $2 / 23$ & $1 / 29$ \\
\hline
\end{tabular}




\section{Figure 1}

\section{Experimental stimuli}

Examples of stimuli used in the folk psychology ("theory of mind", Eyes Test) (A) and folk physics (B) experiments (Baron-Cohen et al., 2001).

A

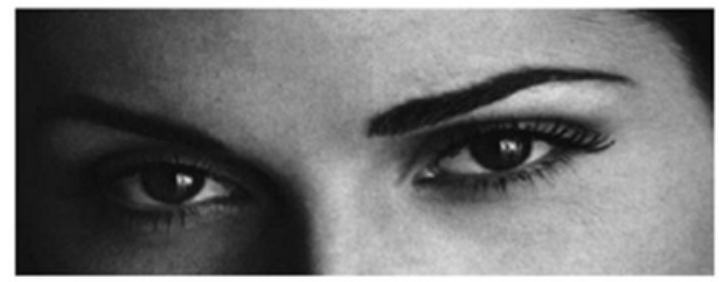

B

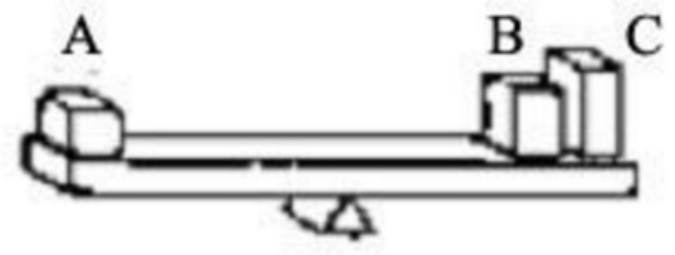

Which box is the heaviest?
a A
b B
$\mathrm{c} \mathrm{C}$
$\mathrm{d}$ all equal
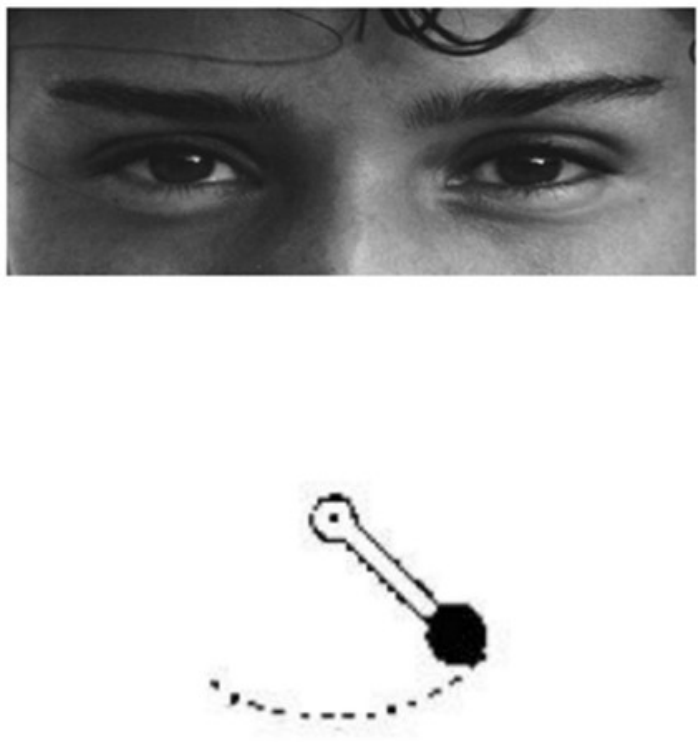

A B C D

Where is the pendulum moving fastest?
a A
b B
c C
d D 


\section{Figure 2}

Results of the experiments

Mean performances on the folk psychology ("theory of mind", Eyes Test) and folk physics tests. Error bars indicate $95 \%$ confidence intervals. CONT - children with negative family history for psychotic disorders (controls), BPD - children of mothers with type I bipolar disorder, SCZ - children of mothers with schizophrenia. ${ }^{*} p<.005, F$ test $(\mathrm{SCZ}<\mathrm{CONT})$

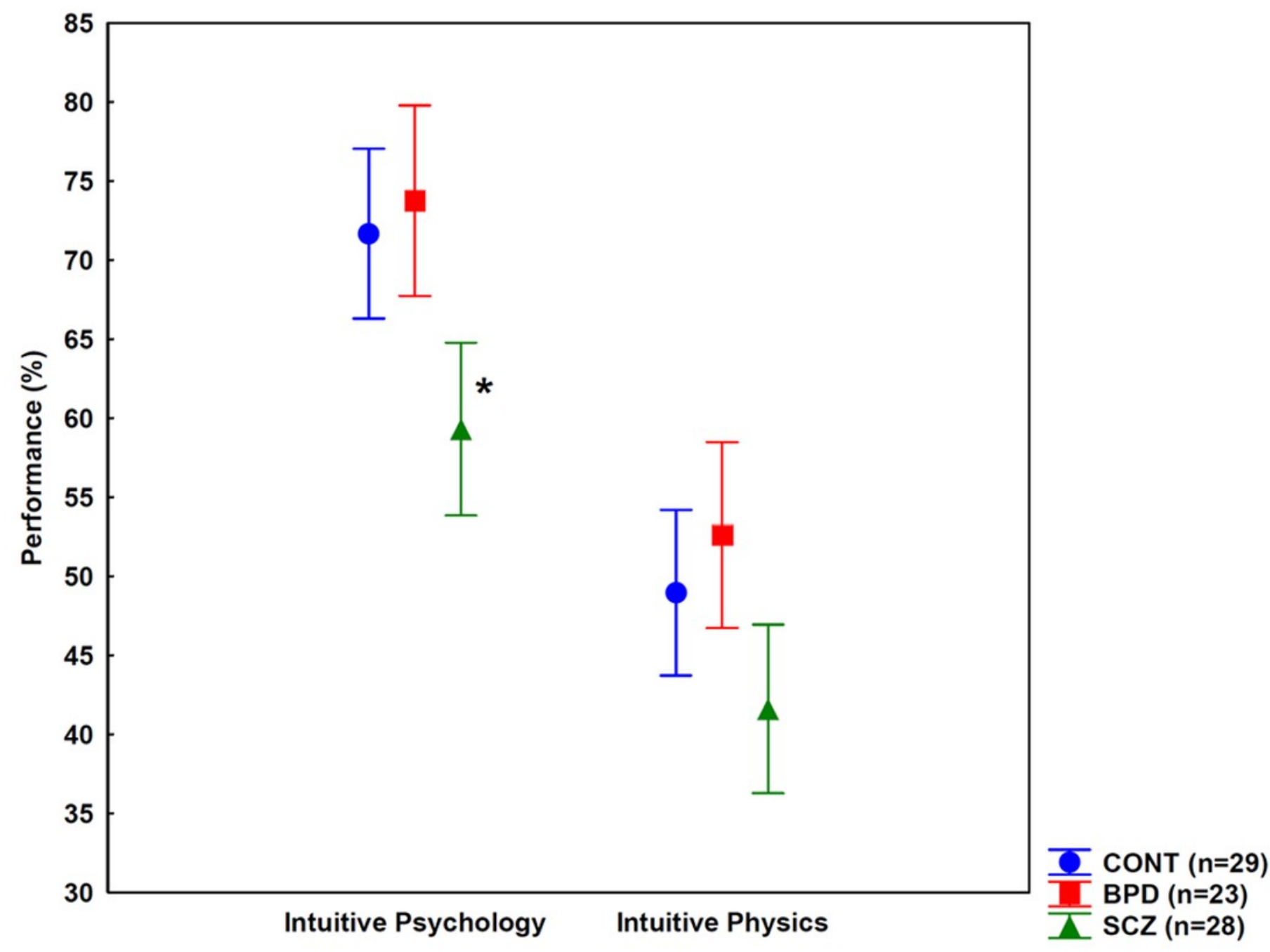

